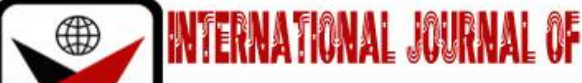

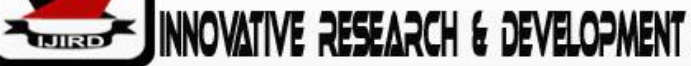

ISSN 2278-0211 (Online)

\section{Decadal Analysis of Land Cover Trend of Federal University of Technology Akure, Ondo State, Nigeria Using Medium Resolution Multi-Temporal Satellite Images}

\begin{tabular}{|c|}
\hline Dr. Ogunlade, S.0 \\
Lecturer, Department of Surveying and Geoinformatics, \\
Federal University of Technology, Akure, Ondo State, Nigeria
\end{tabular}

\begin{abstract}
:
The environment is very important to man. Its continuous existence and sustenance depend on the ability to avoid its mismanagement. Land cover is a fundamental parameter describing the Earth's surface, which is a considerable variable that impacts on and links many parts of the human and physical environments. Thisresearch sought to analyse the trend of Land cover transformation of Federal University of Technology Akure over a decade using medium resolution multi-temporal satellite images (Landsat 1987, TM 2002 and ETM 2017) with the help of satellite remote sensing and GIS techniques. Spatial data were collected over the study period to determine the transformation of the landcover in the study area. The satellite images were subjected to radiometric and atmospheric distortion corrections, pan sharpening enhancement and processing using ENVI 5.3 software; and further subjected to supervised image classification using ArcGIS 10.2 software into five land cover classes which are thick vegetation, light vegetation, grassland, bareland and built up. Land cover maps for each study year were produced and analyzed. The analysis showed that thick vegetation had an increase of 6.9\% from 1987-2002, and a further gain of 4.1\% from 2002-2017. Grassland increased by 6.2\% in the year 1987 to 2002 and diminished with $0.8 \%$ loss from year 2002 to 2017 while bare land experienced a 0.1\% increase from 1987- 2002 and a 3\% increase from 2002 - 2007. Built up areas increased by $10.4 \%$ from $1987-2002$ and 2.2\% from 2002-2017. Light vegetation on the other hand had a $-15.7 \%$ decrease between the year 1987 and 2002 and a further -8.5\% loss between 2002 to 2017. The study observed a steady infrastructural development on the campus responsible for these changes and predicted more transformation by the year 2030. The study recommended a regular and consistent conduct of the analysis of land cover trend for environmental monitoring towards sustainable planning and development.
\end{abstract}

Keywords: Analysis, decade, land cover, multi-temporal, trend

\section{Introduction}

The environment is very important to man (Campbell and Wynne, 2011). Its continuous existence and sustenance depend on the ability to avoid its mismanagement (Ogunlade, 2018). Land cover is a fundamental parameter describing the Earth's surface, and as observed by Balogun., (2011), Ipolliti (2012) and Igbokwe et al., (2016) that which is a considerable variable that impacts on and links many parts of the human and physical environments. Mmom and Nwagwu (2013) viewedland use and land cover of region as a reflection of the level of development in that region, and the level of development influences the land use and land cover. Tata et al., (2018), Ezeomedo and Igbokwe (2012), Eastman (2012) and Ejemeyovwi (2015) viewedland cover as the physical and biological cover of the Earth's surface. Horning (2004) and Eastman (2012) posited that it is generally categorized into build-up areas, vegetation (forests, agricultural areas, grasslands), wetlands, rocks, bare-land and water bodies etc.

Trend is a shift over time among the relationships between the factors that shape the changing nature of humanenvironment relations Mohammadet al., (2017). Land cover data is indispensable to planning and implementation of developmental projects. The analysis of such data give insight into better land utilization as well as play a vital role in the formulation of policies and programme implementation for development over the years (Ejemeyovwi, 2015).Generally, Land use results from the alterations of land cover principally by human through direct use such as for agriculture and livestock raising, forest harvesting and management, urban and sub-urban construction and development (Owoeye and Ibitoye, 2016). Due to anthropogenic activities, the earth surface is being significantly altered by man's presence and several activities on earth (Ogunlade, 2018). Hardly is there any vegetation in the world that has not been affected or altered by man (Oduwaye 2015). Thus Balogun (2011) asserts that about 400,000 hectares of vegetation cover are confirmed to be lost annually. According to Olutoyin et al., (2017), land cover transformation has been asserted to be one of the most important fields of human induced environmental transformation. The environment is facing critical 
challenges due to several factors like increasing population, depletion of natural resources, environmental pollution, unplanned land use and several others (Owoeye and Akinluyi, 2018).

There is the need to update land cover of educational campuses frequently especially those with small aerial coverage and limited land space because according to Oyinloye (2013) and Olutoyin et al.,(2017) landcover is an important factor in geographical analysis, from physical geography studies to environmental analysis and spatial planning approaches; and a dynamic variable that reflects the interaction between socio-economic activities and regional environmental changes.

The incorporation of satellite remote sensing and the techniques Geographical Information System has proven to more effective in recent times especially in natural resource mapping; and a good tool in environmental monitoring and management (Ogunlade, 2018). Satellite sensors offer several advantages over aerial platforms: They can provide a synoptic view (observation of large areas in a single image), fine detail, and systematic, repetitive coverage (Campbell and Wynne 2011). These capabilities and strengths, create, maintain and monitor changes in the many broad-scales environmental analysis. Satellite remote sensing technology has made improvement in the survey and mapping of the global environment over the past two to three decades (Ogunlade, 2019). Repeated imaging enables assessment of changes in the type or condition of surface features. It has impacted the monitoring of land cover changes and provided valuable information necessary for planning and research (Oyinloye, 2013)

The study Area

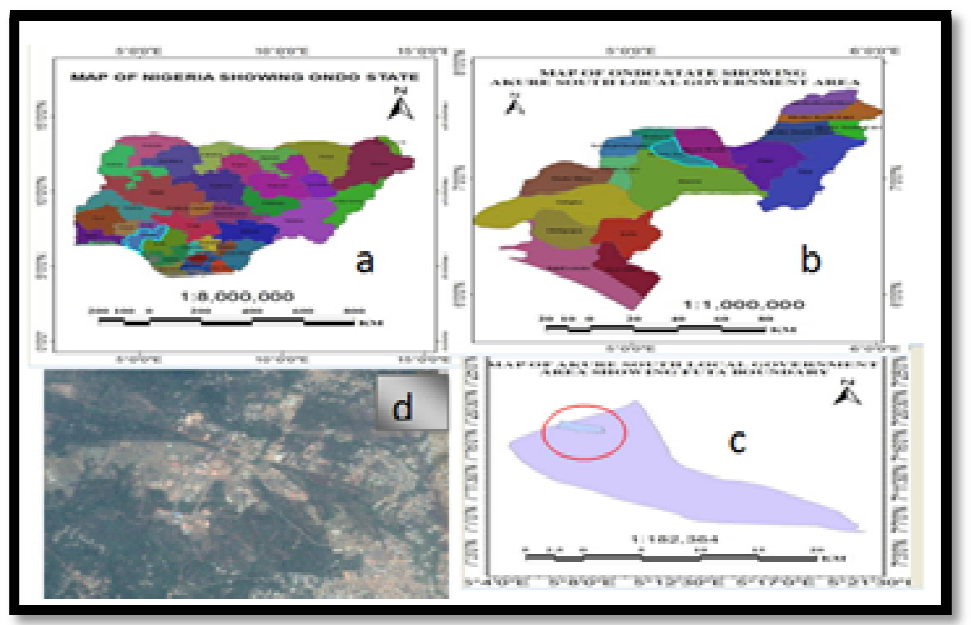

Figure 1: Map of: (a) Nigeria Showing (b) Ondo State Showing (c) Akure South L.G.A (With FUTA In-Set) and (d) Satellite Image of FUTA

The study area is the main campus of the Federal University of Technology Akure Ondo State Nigeria (Figure 1). It has a total land area extent of 577 hectares. The Campus began speedy transformation in the last decade due to population growth of its students and staff as a result of increase in population of the host city Akure and catchment areas (Olisa, 2012). This could sometimes be seen as socio-physical developments which consequently have effects on the natural landscapes and Environment. The extent of this development is however deemed to be monitored in order to guide decision makers on the distribution of facilities/infrastructures and also to ensure that the growth is compatible with the concept that embraces Environmental Sustainability (Oyinloye and Olisa, 2012).Therefore according to Oyinloye and Fasakin(2014)there is the need to conduct investigation on the level of change in the land cover over the past decades so as to understand the trend of the Land Cover which will help in infrastructural development planning and to achieve a sustainable Environment for Learning (Oyinloye,2012).

\section{Materials and Methods}

The objectives of the research were to identify the Land Cover of Federal University of Technology, Akure using satellite images, to determine the trend of the Land Cover changes within the study period and to analyze the trend with a view to predicting possible changes in the year 2030. To achieve these objectives, the map, Shape file or boundary coordinates and satellite images (1987 Thematic Mapper, 2002 Enhanced Thematic Mapper Plus, 2017 Operational Land Imager / Thermal Infrared Sensor) of study area; ENVI 5.3 software, ArcGIS 10.2 and Microsoft office suite software were acquired and stored in a designated computer folder. The satellite images were subjected to radiometric correction, atmospheric correction and noise reduction using FLAASH module in ENVI 5.3 software. The corrected images were subjected to enhancement process so as to present them for good quality interpretation. Pan-Sharpening (integrating high-resolution $(15 \mathrm{~m})$ panchromatic band and low resolution $(30 \mathrm{~m})$ multispectral bands to create a single high-resolution colour image) was the enhancement performed on the satellite imageries due to the fact that the study area is so small that visibility for interpretation will be difficult in a low resolution $(30 \mathrm{~m})$ image. The enhanced images were then subjected to composite generation to obtain combination of RGB bands that will give colored view that appeals to human vision and interpretation, and helps in further analysis. The boundary shape file (.shp) of the study area was thereafter used in sub-setting or clipping the pan sharpened images (Figure 2) using ArcGIS 10.2 software for easy processing. 


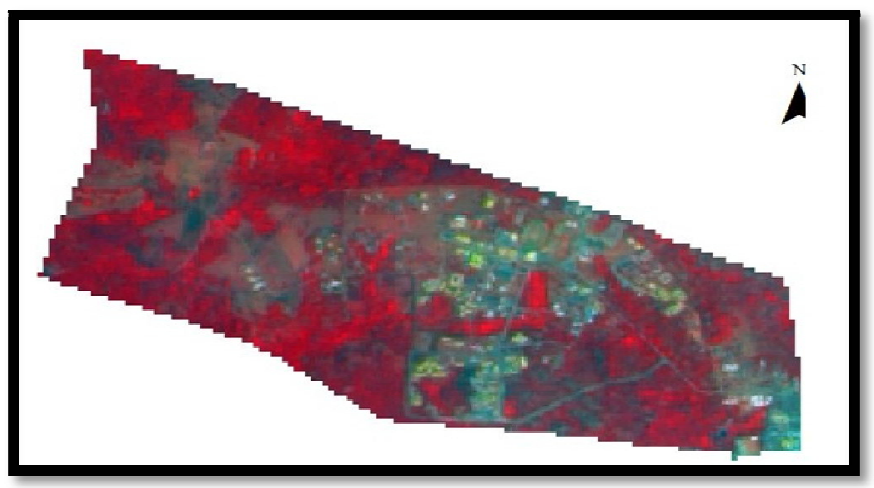

Figure 2: Clipped Pan Sharpened Image of the Study Area

A supervised Image classification was carried out on the images using Arc Map module in the ArcGIS 10.2 software into five classes: Built-up, Thick Vegetation, Light Vegetation, Grass Land and Bareland. After the supervised classification was executed, post classification processes were carried out to polish the images like smoothing and aggregation to remove some unnecessary pixels. Accuracy assessment using ground truthing was carried out to verify and authenticate the classification. To find out how much each of the feature class has change over time, the area for each of the feature class in each epoch was computed from the classified images with the aid of ArcGIS 10.2 software using the Add Area tool of their respective attribute tables. The area column of each of the classified images was exported to Microsoft Excel software package where trend analyses like epoch to epoch change of each feature class, percentage change of each feature class, rate of change of each feature between epochs and projection etc. were carried out, after which graphical representations were prepared.

\section{Results}

Land cover maps, tables and charts for the study years were produced from the classification to aid the analysis. Thus, Figure 3(a, b, c) shows the land cover maps of the study area, Figure 6 shows the chart of area and percentage area coverage of each Land cover type, Figure 7 shows the chart of percentage area coverage of each land cover type for each of the study years.

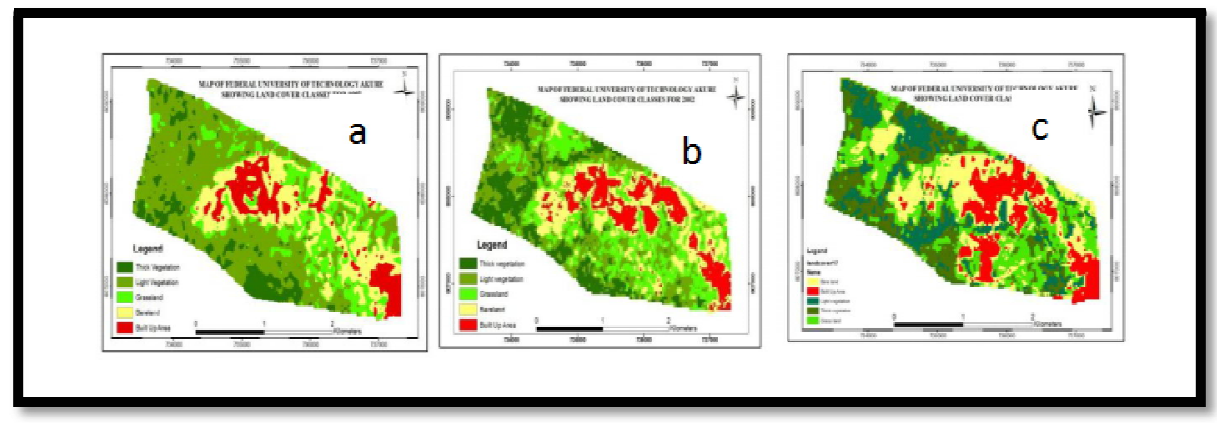

Figure 3: Land Cover Maps of the Study Area in (a) 1987 (b) 2002 (c) 2017

Table 1 shows accuracy assessment results while Table 2 shows the area and percentage area coverage of each land cover type for each study years. These presentations were used as the basis for the analysis of the trend of the land cover change in the study area and their future prediction. The result of the accuracy assessment shows that the maps are reliable enough for analysis.

\begin{tabular}{|c|c|c|}
\hline Year & Overall Accuracy (\%) & Kappa Statistics \\
\hline 1987 & 76.1 & 0.75 \\
\hline 2002 & 82.3 & 0.81 \\
\hline 2017 & 84.1 & 0.83 \\
\hline
\end{tabular}

Table 1: Accuracy Assessment Results

\begin{tabular}{|l|l|l|l|l|l|l|}
\hline \multicolumn{1}{|c|}{ Land Cover } & $\begin{array}{c}1987 \\
(\mathrm{Hts})\end{array}$ & $\begin{array}{c}1987 \\
(\%)\end{array}$ & $\begin{array}{c}2002 \\
(\mathrm{Hts})\end{array}$ & $\begin{array}{c}2002 \\
(\%)\end{array}$ & $\begin{array}{c}2017 \\
(\mathrm{Hts})\end{array}$ & $\begin{array}{c}2017 \\
(\%)\end{array}$ \\
\hline Thick Vegetation & 60.698 & 10.7 & 99.659 & 17.6 & 122.809 & 21.7 \\
\hline Bare land & 111.319 & 19.6 & 112.041 & 19.7 & 129.031 & 22.8 \\
\hline Light Vegetation & 231.973 & 40.9 & 143.216 & 25.2 & 94.744 & 16.7 \\
\hline Grass land & 103.661 & 18.3 & 139.222 & 24.5 & 134.706 & 23.8 \\
\hline Built-Up Area & 58.904 & 10.4 & 73.196 & 12.9 & 85.877 & 15.1 \\
\hline
\end{tabular}

Table 2: Area and Percentage Area Coverage of Land Cover for Each Study Years 


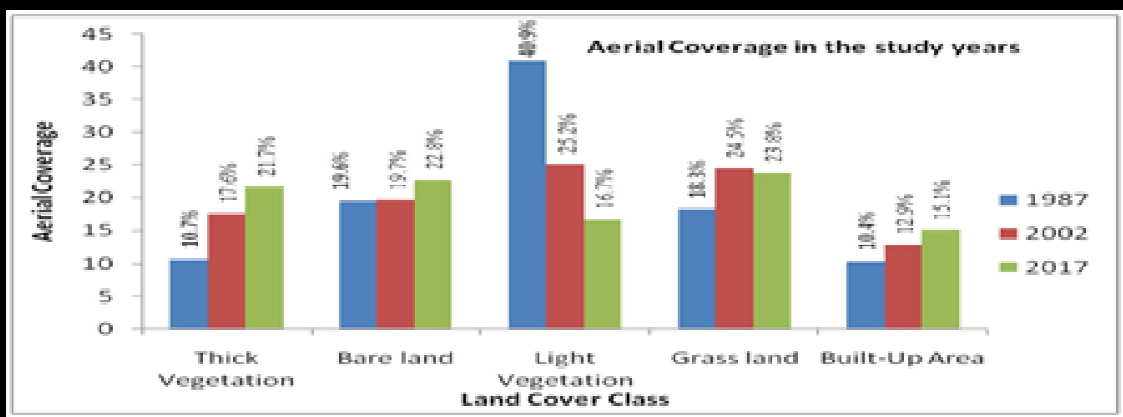

Figure 4: Area and Percentage Area Coverage of Land Cover for Each Study Years

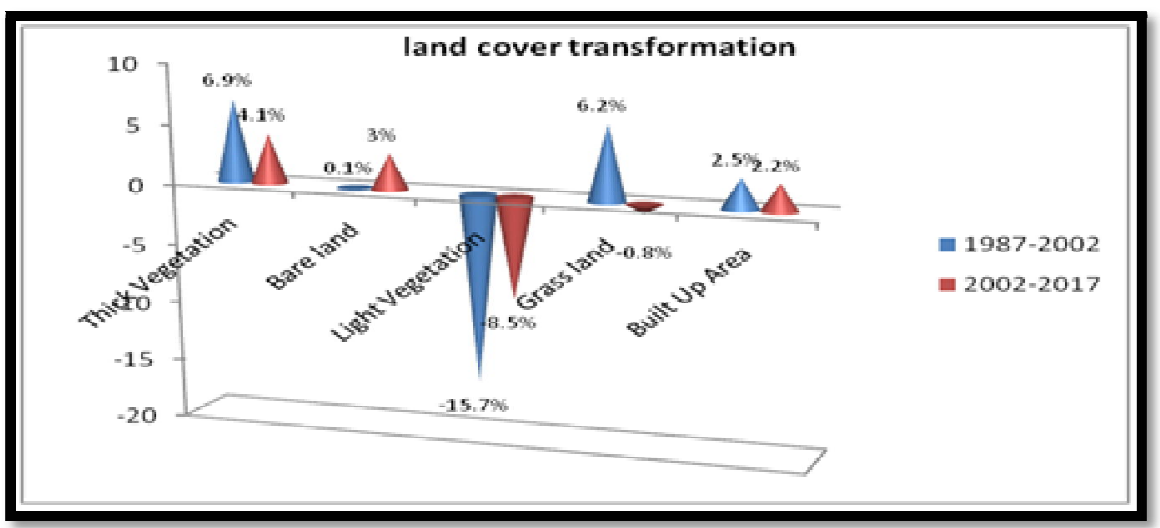

Figure 5: Land Cover Transformation

The analysis showed that there have been steady increased in the thick Vegetation by $6.9 \%$ (38.96 hectares) between the year 1987 and 2002, whichincreased furtherby 4.1\% (23.15 hectares) in 2017. This is adduced to the effort of some departments at faculty of School of Agriculture and Agricultural technology e.g. Forestry and Wood Technology for preservation of the trees. Grassland had a 6.2\% increase between 1987 and 2002 but diminished by $0.8 \%$ (4.52 hectares) in 2017. Bare land also experiences steady increase of $0.1 \%$ ( 0.72 hectares) between year 1987 and 2002 and a gain of 3.0\% (16.99 hectares) between 2002 and 2017. Light vegetation on the other hand decreased by $15.7 \%$ between 1987 and 2002 and a decreased further by $8.5 \%$ between 2002 and 2017. These transformations of vegetation land cover types have been as a result of clearing and opening new spaces for various infrastructure development going on in the Federal University of Technology Akure. This is confirmed by a consistent increase in Built up areas from 1987 to 2002 by $10.4 \%$ (14.29 hectares) and a further gain of $2.2 \%$ (12.68 hectares) in 2017. New building constructions from the Federal Government NEEDS assessment, donations by individuals, corporate organizations, various alumni, cooperative societies have been evidenced in the Federal University of Technology Akure and still going on (Figure 6).

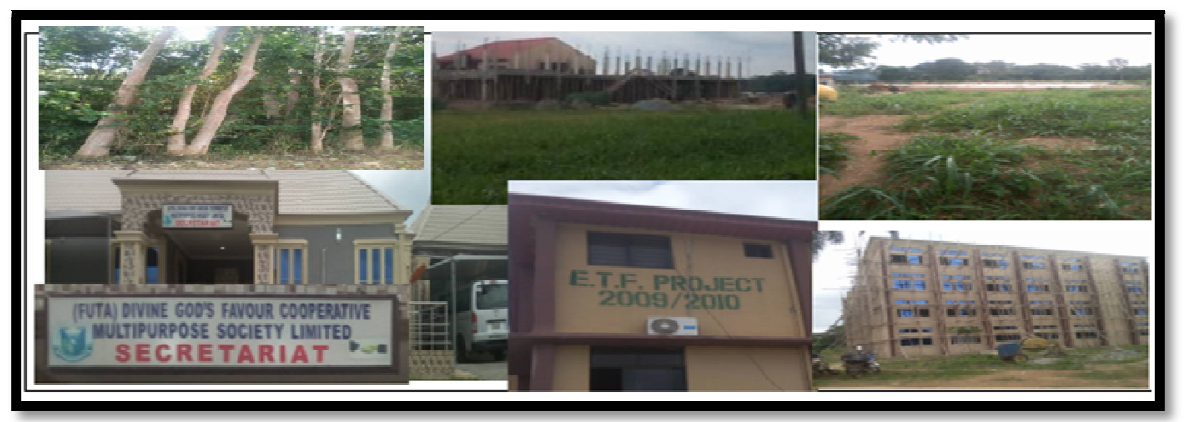

Figure 6: Different Inputs in the Study Area Responsible for Land Use Transformation

\section{Projection of Land Cover Transformation to Year 2030}

The global sustainable development goals targeted the year 2030 as their year of accountability United Nations 2015). Hence the research tends to project these land cover transformations to year 2030. Figure 7 shows the possible expectation in the year 2030 as calculated by:

Changes $=\frac{\text { Changes between base year and recent year }}{\text { Time differences between base year and recent year }} \mathrm{x}$ predicted number of years Equation 1 


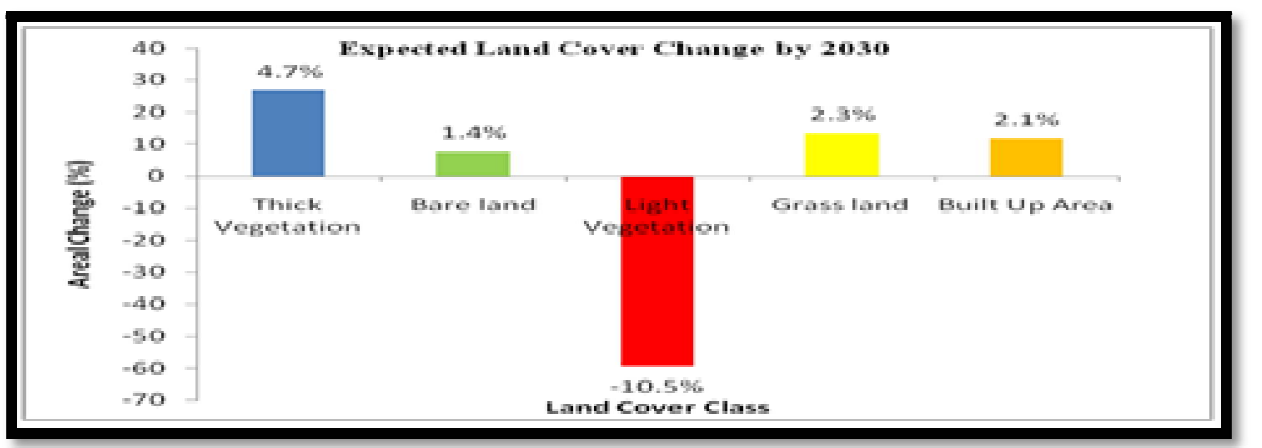

Figure 7: Expected Landcover Transformation by 2030

Figure 7 revealed that by year 2030 thick vegetation is expected to gain a $4.7 \%$ increase possibly due to a progressive activity of the school of agricultural technology to preserve the green ecosystem by planting more trees and conserving the ones on ground. Bareland is expected have 1.4\% gain probably because more space will be opened for infrastructural development such as roads and parks. Light vegetation on the other hand is expected to have a $10.5 \%$ decrease, which will be due to clearing for various infrastructural developments. Grass land is expected to have a gain of $2.3 \%$ probably due inevitable crop farming and horticultural aesthetics. FUTA produces foods for the community so crop farming is inevitable. Bult-up area is expected to have a gain of $2.1 \%$ probably due to consistent inevitable infrastructural development especially construction of new buildings and renovation of existing ones. Thus, transformation of the landcover has been in existence.

\section{Conclusion}

The study has revealed a progressive transformation of the land cover in the study area. The study area has a definite areal extent of 577 hectares of land out which each land cover took its share. The spatial extent remains constant but the landcover keeps transforming. Infrastructural development is always the gain of the resultant effect of all transformations while the rest land cover class suffers the loss. There must a balance of the global goals of maintain and sustaining the green ecosystem, building resilient infrastructure, combating climate change and its impacts etc. The study is a helpful material to achieve the global sustainable goals.

\section{Recommendation}

Consequent upon the revelation of inevitable transformation in the land cover class in the study area and its importance to the achievement of the global sustainable development goals, it is thus recommended that a regular and consistent conduct of the analysis of land cover trend in the study area is necessary for its monitoring for sustainable planning and development.

\section{Acknowledgement}

The author will like to acknowledge the United States Geological Survey (USGS) and the Federal university of Technology Akure-Nigeria for the provision of the data used for this study. All thanks to the anonymous reviewers for their useful input.

\section{References}

i. Balogun, I.A.Z., Balogun, A.A., Adeyewa, Z.D., (2011). Landuse-landcover change detection and associated climatic responses in Akure, Nigeria. Part of PhD research presented at the ISP- NCAR Summer Colloquium on African Weather and Climate, 24thuly $-5^{\text {th }}$ August 2011. Boulder, Colorado, USA

ii. Campbell, J.B., Wynne, R.H., (2011). Introduction to remote sensing. 5th ed. The Guilford Press

iii. Eastman, J. R., (2012). Classification of Remotely Sensed Imagery. Idrisi Selva 17.0 Manual Clark Labs, Clark University 950 Main Street, Worcester MA 01610-1477 USA.

iv. Ejemeyovwi, Danny Ochuko (2015) Change detection in landuse / landcover mapping in Asaba, Niger Delta between 1996 and 2015. A remote sensing and GIS approach British Journal of Environmental Sciences Vol.3, No.3, pp.42-61, August 2015

v. Ezeomedo, I. C., Igbokwe, J. I., (2012). Mapping and analysis of landuse and land cover for sustainable Development using medium resolution satellite Images and GIS. International Journal of Engineering Management Science I.J.E.M.S., Vol.3 (4) 2012-513-519. ISSN 2229-600X

vi. Ezeomedo, I., Igbokwe, J.I., (2013). Mapping and Analysis of Landuse and Land Cover for a Sustainable Development Using High Resolution Satellite Images and GIS FIG Working Week 2013 Environment for Sustainability Abuja, Nigeria, 6 - 10 May 2013. TS03B - Remote Sensing for Landuse and Planning, 6421

vii. Horning, N. (2004). Land cover classification methods, Version 1.0.American Museum of Natural History, Center for Biodiversity and Conservation. Available from http://biodiversityinformatics.amnh.org. (accessed on 2018)

viii. There are no sources in the current document.Igbokwe J. I, Ogunlade S.0, Ejikwe J.O and Igbokwe E.C (2016). Mapping and monitoring deforestation in Ondo State Using Remote Sensing Techniques for forest Resources Management. Nigerian Journal of surveying and Geoinformatics; Vol 5, No. 1. 
ix. Ippoliti, E., Clementini, E., Natali, S., (2012). Automatic generation of land use maps from land cover maps In Jérôme Gensel, Didier Josselin and Danny Vandenbroucke: Multidisciplinary Research on Geographical Information in Europe and Beyond. Proceedings of the AGILE'2012 International Conference on Geographic Information Science, Avignon, April, 24-27, 2012. ISBN: 978-90-816960-0-5

x. Julius Oluranti Owoeye and Oyewole Amos Ibitoye (2016) Analysis of Akure Urban Land Use Change Detection from Remote Imagery Perspective Urban Studies Research Volume 2016, Article ID 4673019, 9 pages http://dx.doi.org/10.1155/2016/4673019

xi. Michael Ajide Oyinloye \& Olisa Babatope Sunday., (2014). An Integrated Remote Sensing and GIS Approach in Monitoring Spatial Expansion of Federal University of Technology Akure. Nigeria Global Journal of Science Frontier Research: E Interdiciplinary Vol 14 Issue 1 Version 1.0 Year 2014. Online ISSN: 2249-4626 \& Print ISSN: 0975-5896

xii. Mmom and Florence W. Fred-Nwagwu (2013) Analysis of Landuse and Landcover Change around the City of Port Harcourt, Nigeria. Global Advanced Research Journal of Geography and Regional Planning (ISSN: 2315-5018) Vol. 2(5) pp. 076-086, August, 2013 Available online http://garj.org/garjgrp/index.html

xiii. Mohammad R. H., Alak P., Zahedul and Md. A.Z., (2017). Spatio-Temporal Analysis of Land Use and Land Cover Changes in Chittagong City Corporation, Bangladesh. International Journal of Advancement in Remote Sensing, GIS and Geography, Vol.4, No.2, 56-72. 11 January 2017 ISSN 2321 - 9149(Research Article)

xiv. Oduwaye, L., (2015). Urban Landuse Planning and Reconciliation. Inaugural Lecture Series 2015, University of Lagos, Nigeria.

xv. Ogunlade S.O, (2018). Mapping and Analysis of Spatiotemporal Landuse dynamics of Akure and its Environ. (Doctoral Dissertation). Nnamdi Azikwe University, Awka Nigeria.

xvi. Ogunlade, S.O (2019): Spatiotemporal Landuse Pattern Mapping For Sustainable Development Of Akure City.Journal of Environmental Technology, School of Environmental Technology, Federal University Of Technology Akure, Nigeria. Vol. 1, No.1, pp.21-28.

xvii. There are no sources in the current document.Owoeye, J.0., Akinluyi F 0, (2018). Geospatial analysis of land cover change and urban sprawl trend in Akure region, Nigeria Research Volume 2 Issue 1 - 2018

xviii. Owoeye, J.O., Ibitoye, O.A., (2016). Analysis of Akure Urban Landuse Change Detection from Remote Imagery Perspective. Urban Studies Research; Vol. 2016,Article ID:4673019:1-9; Hindawi Publishing Corporation.

xix. There are no sources in the current document.Oyinloye, M.A., (2013). Geospatial Analysis of Urban Growth The case of Akure, Nigeria. American Journal of Social Issues and Humanities, 3(4):200-212

$x x$. Oyinloye, M.A., Fasakin, J.O., (2014) Modelling Urban Growth From Medium Resolution Landsat Imageries Of Akure, Nigeria. International Journal for Innovation Education and Research.www.ijier.net Vol.2-06, 2014

xxi. Oyinloye, R.O., Oloukoi, J., (2012). Spatio-Temporal Assessment and Mapping of the Landuse Landcover Dynamics in the Central Forest Belt of Southwestern Nigeria. Research Journal of Environmental and Earth Sciences 4(7): 720-730, 2012 ISSN: 2041-0492

xxii. Oyinloye. M.A., Olisa, B.S., (2012). An Integrated Remote Sensing and GIS Approach in Monitoring Spatial Expansion of Federal University of Technology Akure Nigeria. Global Journal of Science Frontier Research: E Interdiciplinary Volume 14 Issue 1 Version 1.0 Year 2014.Global Journals Inc. (USA). Online ISSN: 2249-4626 \& Print ISSN: 0975-5896

xxiii. Tata Herbert, Nzelibe Ifechukwu Ugochukwu and Ajayi, Gabriel Esan.(2018). Spatio-Temporal Analysis of Urban Land Cover Growth Dynamics in Akure South Metropolis, Ondo State Nigeria. American Journal of Earth and Environmental Sciences. Vol. 1, No. 1, 2018, pp. 1-9. 